2000s-58

\title{
Competition and the Reform of Incentive Schemes in the Regulated Sector
}

Marcel Boyer, Jean-Jacques Laffont

\begin{tabular}{c}
\hline Série Scientifique \\
Scientific Series
\end{tabular}

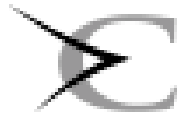

Montréal

Novembre 2000 


\section{CIRANO}

Le CIRANO est un organisme sans but lucratif constitué en vertu de la Loi des compagnies du Québec. Le financement de son infrastructure et de ses activités de recherche provient des cotisations de ses organisationsmembres, d'une subvention d'infrastructure du ministère de la Recherche, de la Science et de la Technologie, de même que des subventions et mandats obtenus par ses équipes de recherche.

CIRANO is a private non-profit organization incorporated under the Québec Companies Act. Its infrastructure and research activities are funded through fees paid by member organizations, an infrastructure grant from the Ministère de la Recherche, de la Science et de la Technologie, and grants and research mandates obtained by its research teams.

\section{Les organisations-partenaires / The Partner Organizations}

-École des Hautes Études Commerciales

-École Polytechnique

-Université Concordia

-Université de Montréal

-Université du Québec à Montréal

-Université Laval

-Université McGill

-MEQ

-MRST

-Alcan Aluminium Ltée

-AXA Canada

-Banque Nationale du Canada

-Banque Royale du Canada

-Bell Québec

-Bombardier

-Bourse de Montréal

-Développement des ressources humaines Canada (DRHC)

-Fédération des caisses populaires Desjardins de Montréal et de l'Ouest-du-Québec

-Hydro-Québec

-Imasco

-Industrie Canada

-Pratt \& Whitney Canada Inc.

-Raymond Chabot Grant Thornton

-Ville de Montréal

(C) 2000 Marcel Boyer et Jean-Jacques Laffont. Tous droits réservés. All rights reserved. Reproduction partielle permise avec citation du document source, incluant la notice ().

Short sections may be quoted without explicit permission, provided that full credit, including ( $)$ notice, is given to the source.

Ce document est publié dans l'intention de rendre accessibles les résultats préliminaires de la recherche effectuée au CIRANO, afin de susciter des échanges et des suggestions. Les idées et les opinions émises sont sous l'unique responsabilité des auteurs, et ne représentent pas nécessairement les positions du CIRANO ou de ses partenaires.

This paper presents preliminary research carried out at CIRANO and aims at encouraging discussion and comment. The observations and viewpoints expressed are the sole responsibility of the authors. They do not necessarily represent positions of CIRANO or its partners.

\section{ISSN 1198-8177}




\title{
Competition and the Reform of Incentive Schemes in the Regulated Sector*
}

\author{
Marcel Boyer ${ }^{\dagger}$, Jean-Jacques Laffont ${ }^{\ddagger}$
}

\begin{abstract}
Résumé / Abstract
Nous analysons dans un modèle principal-agent avec sélection adverse et contrats complets comment les incitations dans une entreprise réglementée sont affectées par la concurrence externe à travers son effet sur l'information et la fonction objectif du principal d'une part et les contraintes de compatibilité incitative et de rationalité individuelle de l'agent d'autre part. Nous considérons plus précisément les sources suivantes de pressions concurrentielles accrues : une meilleure structure d'information, une menace plus forte de liquidation, une concurrence plus intense pour le talent, un secteur privé plus efficace, et l'existence de meilleurs substituts. Nous caractérisons dans chaque cas les conditions sous lesquelles l'effet sur les incitations est positif.

We consider a regulation problem with complete contracting in a principal-agent model with adverse selection and review within this model the various channels by which external competition parameters affect incentives within the regulated firm. The channels are: the principal's information, the principal's objective function, the agent's incentive constraint, the agent's participation constraint. We consider in particular a better information structure, a threat of liquidation, a fight for talent, a more efficient private sector, and the existence of better substitutes. We characterize in each case the conditions under which the effect on incentives is positive.
\end{abstract}

Mots Clés : Incitations secteur public, concurrence

Keywords: Public sector incentives, competition

\footnotetext{
* Corresponding Author: Marcel Boyer, CIRANO, 2020 University Street, 25 ${ }^{\text {th }}$ floor, Montréal, Qc, Canada H3A 2A5 Tel.: (514) 985-4002 Fax: (514) 985-4035 email: boyerm@cirano.umontreal.ca We thank participants in the Canadian Economic Theory Conference (Ottawa) and in the microeconomic seminar at Rutgers University for their comments. Financial support from the SSHRC (Canada) and CNRS (France) is gratefully acknowledged.

† Université de Montréal and CIRANO

¥ Institut Universitaire de France, GREMAQ, IDEI and Université de Toulouse I
} 


\section{INTRODUCTION}

The globalization of national economies and the pace of technological progress increase the overall level of competition locally and globally. This in turn raises questions regarding the economic role of the State as a regulator of economic activities. Demands for profound reforms of the regulated sector and government institutions are expressed in numerous countries. Indeed most countries have designed and begun implementing reforms aimed at increasing the performance of their regulated sector. The OECD public management service (PUMA) provides numerous examples of national policies towards that goal. A significant example among many is the implementation in England of Compulsory Competitive Tendering (CCT) procedures at the municipal and regional levels. The local authorities must call for tenders for an increasing array of government services before deciding whether those services will be offered by a direct municipal service organization or a private company under different forms of delegated management contracts with the local authorities. ${ }^{1}$ The underlying leitmotifs are performance, incentives and competition of one kind or another. ${ }^{2}$ The preferred path of public sector reform has generally been to privatize and liberalize former public sectors. ${ }^{3}$ However, many activities will and must remain under government's direct control for natural monopoly or national interest reasons. How incentives, within public firms and institutions or within regulated private firms, should respond to this more competitive environment $?^{4}$

In this paper, we study a regulation problem with complete contracting and a benevolent regulator (the principal) in a principal-agent model with adverse selection. We analyze the comparative statics effects on the power of incentives in the regulated firm or administration (the agent) of various parameter changes usually associated with greater competitive pressures. This is a necessary step to explore how greater competitive pressures may affect incentives when

\footnotetext{
${ }^{1}$ See LeGallo (1998).

${ }^{2}$ There exists also an important literature which has investigated Machlup's (1967) claim that there is no managerial slack when a firm operates in a perfectly competitive output market. Leibenstein (1966) has provided empirical evidence from case studies supporting the common view that increasing competition reduces slack.

${ }^{3}$ It is often accompanied by sizable downsizing. See Jeon and Laffont (1999) for a study of the incentive problems created by downsizing.

${ }^{4}$ One possibility is sometimes to introduce competition within the regulated sector itself. However, this often requires wasteful duplications so that competition will remain limited for example to duopolies or restricted oligopolies. Auriol and Laffont (1992) have investigated the changes on incentives brought about by this duopoly structure. See also Dana and Speir (1994) and Anton and Yao (1989, 1992).
} 
regulation is imperfect or captured. One major difficulty in this context resides in the fact that there is no single definition of what increased competition means.

The level of competitive pressures exerted on the public sector may be directly decided by the government when activities which were monopolies are liberalized. We want to explore a more indirect notion of increased competitive pressures. The level of competition itself is not an exogenous parameter as emphasized by Bliss and Di Tella (1997) who criticize the modeling of greater competition by the increase in the number of competitors which is an endogenous variable at the industry level. They suggest that more fundamental parameters, such as transport costs, cost uncertainty, distribution and overhead cost, should be used. We recognize the importance of this point and we will follow their suggestion as much as possible. However, for our purpose, a partial equilibrium analysis which considers changes in parameters of the environment (which are indeed endogenous in a more general analysis) is sufficient to understand some of the links by which increased competition affects incentives in the regulated sector. We consider such parameters, namely the information structure, the threat of bankruptcy, the opportunities available to agents, the technologies and the quality of substitutes.

The paper is organized as follows. We discuss the relevant literature in Section 2 followed by the presentation of the basic model in Section 3. We study the informational effect in Section 4. We devote Section 5 to the threat of liquidation effect while Section 6 examines competition in talent. The impacts of a more efficient private sector and of improvements in substitutes for the regulated product are investigated in Section 7. We then conclude in Section 8.

\section{COMPETITION AND INCENTIVES.}

To review the literature on competition and incentives, we can regroup the articles according to several criteria. Two such criteria are the type of agency problem considered and the channel by which competition affects incentives. According to the first criterion, papers differ according to the type of model which formalizes the agency problem within the firm, moral hazard or adverse selection. According to the second criterion, papers differ by the channel through which greater competition affects the level of managerial slack, that is, whether it is through an informational 
effect, an incentive constraint effect, a principal's objective function effect, or an individual rationality constraint effect. The informational effect refers to the fact that greater competition may increase the information of the principal about the agent and therefore decrease the cost of asymmetric information. The incentive constraint effect is that greater competition may affect directly the agent's incentive constraint for example by making it easier or more difficult for a good type to mimic a bad type agent. The principal's objective function effect is that greater competition may affect directly the value of production for the principal and consequently the value for him of creating incentives for the agent: the desirable change in production may then affect or not the incentive constraint of the agent. The individual rationality constraint effect conveys the idea that greater competition may increase or reduce the outside opportunities of the agent and therefore her reservation utility level.

We can illustrate this classification in the following matrix. In each cell, we place the papers dealing with a similar agency problem and a similar channel but dealing possibly with different institutional contexts. As indicated in Table 1, our paper fits into four cells. In Holmström (1982), relative performance evaluation, or competition among agents, is used in order to exploit the valuable information conveyed by the other agents' outputs regarding the effort of a given agent. In Nalebuff and Stiglitz (1983) and Shleifer (1985), the principal can infer, from observing the outputs of all agents, some information on the level of effort chosen by a given agent and therefore competition enables the design of more efficient reward structures. ${ }^{5}$ In Hart (1983) and Scharfstein (1988), competition between entrepreneurial firms and managerial firms makes it more difficult for managers to shirk. Hart (1983) shows that the market system by itself makes the actions and utilities of different managers interdependent via prices. ${ }^{6}$ Scharfstein (1988) shows that the net effect of competition on managerial slack depends on managerial preferences and the number of states and therefore, incentive problems are not always mitigated by greater competition. Increasing the number of bidders in an auction of contracts with adverse selection

\footnotetext{
${ }^{5}$ The yardstick competition argument was further extended to agents with different but correlated characteristics by Crémer and McLean $(1985,1988)$ for a principal who is a discriminating monopolist or an auctioneer, and by Riordan and Sappington (1988) when regulating a firm with an ex post signal correlated with the firm's characteristics.

${ }^{6}$ Competition makes the performance of different firms interdependent but the impact on incentives works in a different way from Holmström (1982). While the latter assumed that the performances of similar firms could be observed by the principal and therefore used in compensation schemes, they are not in Hart's analysis.
} 
as in Laffont and Tirole (1987) also affects the incentive constraints of the agents.

\section{TABLE 1}

\begin{tabular}{c|c|c|} 
& Moral & $\begin{array}{c}\text { Adverse } \\
\text { Selection }\end{array}$ \\
\hline $\begin{array}{c}\text { Information } \\
\text { structure }\end{array}$ & $\begin{array}{c}\text { Holmström (1982) } \\
\text { Hermalin (1992) }\end{array}$ & $\begin{array}{c}\text { Nalebuff and Stiglitz (1983) } \\
\text { Shleifer (1985) } \\
* \text { THIS PAPER (PROP.1,2)* }\end{array}$ \\
\hline $\begin{array}{c}\text { Incentive } \\
\text { constraint }\end{array}$ & Hermalin (1992) & $\begin{array}{c}\text { Schmidt (1997) } \\
\text { Scharfstein (1988) }\end{array}$ \\
\hline $\begin{array}{c}\text { Principal's } \\
\text { objective } \\
\text { function }\end{array}$ & Hermalin (1994) & Schmidt (1997) \\
\hline $\begin{array}{c}\text { Participation } \\
\text { constraint }\end{array}$ & & $*$ THIS PAPER (PROP.3)* \\
\hline
\end{tabular}

In Hermalin (1992), the manager makes an offer to the owner-shareholder through a contract satisfying a participation constraint for the shareholders and an incentive condition for the agent. More competition may reduce the agent's expected utility or income, thereby generating a negative direct income effect by which the consumption of perks or slack are reduced. But a more competitive environment means better informed shareholders regarding the actions taken by the agent, increasing the agent's net-of-risk-premium income and generating a positive income effect in favor of less effort. The competition effect is therefore ambiguous. In Hermalin (1994), principal-agent hierarchies compete in the same market. Weak incentives may be the best response to strong incentives because the value of incentives is proportional to the firm's lower expected production level. But an increase in the number of competitors generates a substitution 
effect along the best reply function and a strategic effect, the rivals' production being sensitive to the firm's lower cost. Hence, more competition has an ambiguous effect. Finally, in Schmidt (1997), competition affects incentives through a positive threat-of-liquidation effect, inducing the manager to work harder, and a negative profit-reduction effect making it less valuable for the principal to implement strong incentive schemes. He obtains that increased competition may increase or reduce managerial slack given the opposite signs of the two main effects identified. Moreover, increasing competition may lower managerial slack when competition is low but increase managerial slack when competition is already intense.

\section{THE MODEL}

We consider a natural monopoly ${ }^{7}$ which realizes a public project valued $S$ at a cost of

$$
C=\beta-e
$$

where

- $\beta \in\{\underline{\beta}, \bar{\beta}\}$ is a parameter of cost efficiency which is privately known by the manager, where $\Delta \beta=\bar{\beta}-\underline{\beta}>0$; let $\nu=\operatorname{Pr}(\beta=\underline{\beta})$ be the common knowledge probability that the firm is a low cost firm; we will refer to a $\underline{\beta}$ firm as a good type firm and to a $\bar{\beta}$ firm as a bad type firm;

- $e$ is the manager's effort level which has a disutility $\psi(e)$ with $\psi^{\prime}>0, \psi^{\prime \prime}>0, \psi^{\prime \prime \prime} \geq 0$; let $\phi(x)=\psi(x)-\psi(x-\Delta \beta) ;$

- $C$ is observable by the public regulator; we take the accounting convention that it is directly paid by the regulator.

The firm's utility level is then

$$
U=t-\psi(e)
$$

\footnotetext{
${ }^{7}$ See Laffont and Tirole (1993) for a more detailed exposition.
} 
where $t$ is the monetary transfer from the regulator to the firm. This transfer has a per-unit social opportunity cost of $1+\lambda$ with $\lambda>0$. Consumers' welfare is

$$
S-(1+\lambda)(t+\beta-e)
$$

and social welfare is taken to be

$$
W=S-(1+\lambda)(t+\beta-e)+U=S-(1+\lambda)(\psi(e)+\beta-e)-\lambda U
$$

Under complete information the regulator would maximize social welfare under the individual rationality constraint of the firm, that is, $U \geq 0$. Optimal regulation would lead to efficient effort levels $\psi^{\prime}(e)=1$ or $e=e^{*}$ for both types, and no rents $U=0$ for both types. Under incomplete information, the regulator maximizes expected social welfare under the usual incentive and individual rationality constraints, that is, solves (with obvious notations)

$$
\begin{aligned}
& \max \nu[S-(1+\lambda)(\underline{\beta}-\underline{e}+\psi(\underline{e}))-\lambda \underline{U}] \\
& \quad+(1-\nu)[S-(1+\lambda)(\bar{\beta}-\bar{e}+\psi(\bar{e}))-\lambda \bar{U}] \\
& \text { subject to } \quad \underline{U} \geq \bar{U}+\phi(\bar{e}), \quad \bar{U} \geq \underline{U}-\phi(\underline{e}+\Delta \beta), \quad \underline{U} \geq 0, \quad \bar{U} \geq 0
\end{aligned}
$$

for which the solution is

$$
\begin{array}{ll}
\psi^{\prime}(\underline{e})=1, \quad \psi^{\prime}(\bar{e})=1-\frac{\lambda}{1+\lambda} \frac{\nu}{1-\nu} \phi^{\prime}(\bar{e})<1 \\
\underline{U}=\phi(\bar{e}), \quad \bar{U}=0
\end{array}
$$

The regulator makes the optimal trade-off between efficiency and rents. He decreases the incentives of the bad type $\left(\bar{e}<e^{*}\right)$ to decrease the rent of the good type $\phi(\bar{e})$.

Such a mechanism can be implemented by an incentive compatible menu of transfer-cost pairs $\{(\underline{t}, \underline{C}),(\bar{t}, \bar{C})\}$ : the good type firm chooses the first pair, implying the efficient level of effort $\left(\underline{C}=\underline{\beta}-e^{*}\right)$ and a positive rent $\underline{U}=\underline{t}-\underline{C}=\phi(\bar{e})$; the bad type firm chooses the second pair, implying an inefficient level of effort $(\bar{C}=\bar{\beta}-\bar{e})$ and no rent.

¿From (5), incentives of the bad type decrease with increases in $\lambda, \Delta \beta$ and $\nu$. When $\nu$ is higher, the probability of having to give up an informational rent to the good type is higher: 
the expected cost of this rent is higher and distorting downwards the incentives of the bad type reduces this expected cost. However, if $\nu$ is larger than some value $\nu^{*}$, it is better to give up production by the bad type and offer a contract with no rent to the good type. The incentives of the only active firm are then maximal, as always. The value of $\nu^{*}$ is determined by the equality of expected welfare with and without the bad type firm, that is, using (5):

$$
\left(1-\nu^{*}\right)\left[S-(1+\lambda)\left(\bar{\beta}-\bar{e}\left(\nu^{*}\right)+\psi\left(\bar{e}\left(\nu^{*}\right)\right)\right)\right]=\lambda \nu^{*} \phi\left(\bar{e}\left(\nu^{*}\right)\right)
$$

We want to study the effect of competition on this optimal trade-off between efficiency and rents. We start by considering the informational effect of competition.

\section{THE INFORMATIONAL EFFECT OF COMPETITION}

It has often been suggested that competition generates information. Competition allows comparisons and being able to compare is being better informed. Rather than looking deeper into how exactly more competition means more information for the principal or the regulator, we consider in this section how the menu of contracts offered changes when the regulator has access to a better information structure. We provide a general description of this information effect on the power of incentives before looking at special cases.

We model this better information structure as the possibility for the regulator to observe a signal correlated with the true type of the firm before designing the contracts and determining in particular the effort level to be induced from the bad type firm. However, contrary to the literature reviewed in the introduction, we assume that this signal is non verifiable and cannot be used to condition the contract. It is the way yardstick competition works in practice, for example in the telecommunication and electricity sectors. We then proceed with the comparative statics analysis of a better information or signal.

\subsection{Competition as a better information structure}

An information structure for the regulator is a set of signals $\Sigma=\left\{\sigma_{1}, \sigma_{2}, \ldots, \sigma_{I}\right\}$ and conditional probabilities $\operatorname{Pr}\left(\sigma_{i} \mid \underline{\beta}\right), \quad i=1, \ldots, I$. For each signal $\sigma_{i}$ the regulator computes his posterior 
belief that the firm is of type $\underline{\beta}$ :

$$
\hat{\nu}_{i}=\operatorname{Pr}\left(\underline{\beta} \mid \sigma_{i}\right), \quad i=1, \ldots, I
$$

and an associated strength of incentives defined by the level of effort of the bad type

$$
\psi^{\prime}\left(\bar{e}_{i}\right)=1-\frac{\lambda}{1+\lambda} \frac{\hat{\nu}_{i}}{1-\hat{\nu}_{i}} \psi^{\prime \prime}\left(\bar{e}_{i}\right)
$$

when the regulator wants to keep both types of firms. Let $\bar{e}_{i}=Z\left(\frac{\hat{\nu}_{i}}{1-\hat{\nu}_{i}}\right)=\hat{Z}\left(\hat{\nu}_{i}\right)$ denote the solution of $(8){ }^{8}$

$\underline{\text { Proposition } 1}$ : If $Z$ is concave and $\hat{\nu}_{i}<\nu^{*}$ for all $i$, then the regulator wishes to keep both types of firms and the expected power of incentives decreases when the regulator has access to an informative signal on the private information of the firm.

Proof: By definition,

$$
\mathrm{E}_{\sigma_{i}} \hat{\nu}_{i}=\mathrm{E}_{\sigma_{i}}\left(\mathrm{E}_{\{\underline{\beta}\}} \mid \sigma_{i}\right)=\mathrm{E} 1_{\{\underline{\beta}\}}=\nu .
$$

¿From Jensen's inequality, $\mathrm{E}_{\sigma_{i}} \bar{e}_{i} \leq \bar{e}(\nu)$ iff $\hat{Z}$ is concave. Since $\psi^{\prime \prime}>0, \psi^{\prime \prime \prime}>0$, then $Z$ is a decreasing function. Let $h\left(\hat{\nu}_{i}\right)=\frac{\hat{\nu}_{i}}{1-\hat{\nu}_{i}}$, then $h(\cdot)$ is increasing and convex. Hence, $\hat{Z}^{\prime \prime}=$ $Z^{\prime \prime} h^{\prime 2}+Z^{\prime} h^{\prime \prime}$. Therefore $\hat{Z}$ is concave if $Z^{\prime \prime} \leq 0$. Q.E.D.

We showed above that $\hat{Z}$ is concave if $\psi(\cdot)$ is quadratic or if $\lambda$ is small enough. Note also that if we define a signal $\sigma_{i}$ as being favorable [unfavorable] if $\hat{\nu}_{i}>\nu_{i}\left[\hat{\nu}_{i}<\nu_{i}\right]$, the power of incentives

${ }^{8}$ Differentiating (8) twice and substituting, we obtain

$$
\hat{Z}^{\prime \prime}(\hat{\nu})=-\frac{\hat{Z}^{\prime 2}\left(\psi^{\prime \prime \prime}+\frac{\lambda}{1+\lambda} \frac{\hat{\nu}}{1-\hat{\nu}} \psi^{\prime \prime \prime \prime}\right)+2 \hat{Z}^{\prime} \frac{\lambda}{1+\lambda} \frac{1}{(1-\hat{\nu})^{2}} \psi^{\prime \prime \prime}+\frac{\lambda}{1+\lambda} \frac{2}{(1-\hat{\nu})^{3}} \psi^{\prime \prime}}{\psi^{\prime \prime}+\frac{\lambda}{1+\lambda} \frac{\hat{\nu}}{1-\hat{\nu}} \psi^{\prime \prime \prime}} .
$$

Therefore, if $\psi(e)$ is quadratic $\left(\psi^{\prime \prime}=\alpha\right.$, where $\alpha$ is a positive constant; $\left.\psi^{\prime \prime \prime}=0\right)$, we obtain

$$
\hat{Z}^{\prime \prime}(\hat{\nu})=-\frac{\lambda}{1+\lambda} \frac{2}{(1-\hat{\nu})^{3}} \alpha<0 .
$$

Similarly, if $\lambda \rightarrow 0$, we obtain

$$
\hat{Z}^{\prime \prime}(\hat{\nu})=-\frac{\frac{2}{(1-\hat{\nu})^{3}} \psi^{\prime \prime}}{\frac{1+\lambda}{\lambda} \psi^{\prime \prime}+\frac{\hat{\nu}}{1-\hat{\nu}} \psi^{\prime \prime \prime}}<0 .
$$

Therefore, $\hat{Z}$ is concave if $\psi(\cdot)$ is quadratic or if $\lambda$ is small enough. 
decreases [increases] after a signal which is favorable [unfavorable]. In the extreme case where the regulator, observing a favorable signal, keeps only the good type firm, that is, where $\hat{\nu}_{i}>\nu^{*}$ for all favorable signals, it is obvious that the expected power of incentives increases since it increases when the signal is unfavorable and since the bad type firm is dropped when the signal is favorable.

Proposition 2 : The expected power of incentives of the active firms increases with the availability of a signal correlated with the true $\beta$ iff, for all favorable signals $\left(\hat{\nu}_{i}>\nu_{i}\right)$, we have $\hat{\nu}_{i}>\nu^{*}$.

Between the two extreme regimes defined by propositions 1 and 2, the expected power of incentives may increase or decrease depending on the probabilities of the signals leading to the liquidation of the bad type firm. We now illustrate these two propositions with four relevant cases.

\subsection{Four Special Cases}

Case 1: A general non-degenerate signal.

We first assume that competition allows the regulator to obtain imperfect but valuable information on the cost function of the firm. We model this form of yardstick competition as follows: the regulator can observe an informative signal $\sigma \in\{\underline{\sigma}, \bar{\sigma}\}$ correlated with the true type of the firm, that is,

$$
\begin{aligned}
& \operatorname{Pr}(\underline{\sigma} \mid \underline{\beta})=\operatorname{Pr}(\bar{\sigma} \mid \bar{\beta})=\mu \geq \frac{1}{2} \\
& \operatorname{Pr}(\bar{\sigma} \mid \underline{\beta})=\operatorname{Pr}(\underline{\sigma} \mid \bar{\beta})=1-\mu .
\end{aligned}
$$

As $\mu$ increases, the informativeness of the signal increases, that is, the regulator's confidence in the signal increases. We want to investigate the effect of an increase in $\mu$ on the power of incentives. For reasons of simplicity, let us consider the special case where $\psi(e)=\frac{1}{2} \alpha e^{2}$ with $\Delta \beta=1$. As long as the regulator wants to keep both types of firms, we find that:

$$
\frac{d \mathrm{E} \bar{e}}{d \mu}<0
$$


a direct illustration of Proposition $1 .^{9}$ In a sense, the cost of implementing a larger effort from the bad type firm increases [decreases] with $\mu$ following a favorable [an unfavorable] signal because $\sigma$ is then a more reliable predictor of the efficiency of the firm. Observing $\underline{\sigma}[\bar{\sigma}]$ implies a higher [lower] probability that an informational rent will be captured by the firm, hence an increase [a decrease] in incentives.

There is a value $\mu^{*}$ defined by

$$
\frac{\nu \mu^{*}}{\nu \mu^{*}+(1-\nu)\left(1-\mu^{*}\right)}=\nu^{*}
$$

where $\nu^{*}$ is defined by (7), beyond which the bad type firm is shut down after a favorable signal $\underline{\sigma}$ but remains active after an unfavorable signal $\bar{\sigma}$. ¿From then on, the expected effort of the bad type increases with $\mu$ and reaches the efficient level when $\mu=1$ (See Figure 1). Proposition 1 holds for $\mu<\mu^{*}$ and Proposition 2 holds for $\mu>\mu^{*}$.

With more signals, we have the following situation, illustrated in Figure 2. For $\mu<\mu_{1}$, Proposition 1 holds and expected incentives decrease. When $\mu$ reaches $\mu_{1}$, the bad type firm is dropped after signal $\sigma_{4}$. When $\mu$ reaches $\mu_{2}$, the bad type firm is dropped after signal $\sigma_{3}$. Between $\mu_{1}$ and $\mu_{2}$ the expected incentives can decrease or increase depending on the probability of $\sigma_{4}$. For $\mu>\mu_{2}$, Proposition 2 holds and expected incentives increase. The transition between the two extreme cases depends finely on the specifics of the problem.

\footnotetext{
${ }^{9}$ Let $\underline{\nu}$ and $\bar{\nu}$ be the posterior probabilities that the firm is of the good type after observing $\underline{\sigma}$ and $\bar{\sigma}$ respectively. We have

$$
\frac{\underline{\nu}}{1-\underline{\nu}}=\frac{\nu}{1-\nu} \frac{\mu}{1-\mu} \text { and } \frac{\bar{\nu}}{1-\bar{\nu}}=\frac{\nu}{1-\nu} \frac{1-\mu}{\mu}
$$

The effort level of a bad type firm after a favorable signal is then

$$
\bar{e}(\underline{\sigma})=\frac{1}{\alpha}-\frac{\lambda}{1+\lambda} \frac{\nu}{1-\nu} \frac{\mu}{1-\mu} \quad ; \quad \frac{d \bar{e}(\underline{\sigma})}{d \mu}<0, \quad \frac{d^{2} \bar{e}(\underline{\sigma})}{d \mu^{2}}<0
$$

Similarly after an unfavorable signal

$$
\bar{e}(\bar{\sigma})=\frac{1}{\alpha}-\frac{\lambda}{1+\lambda} \frac{\nu}{1-\nu} \frac{1-\mu}{\mu} \quad ; \quad \frac{d \bar{e}(\bar{\sigma})}{d \mu}>0, \quad \frac{d^{2} \bar{e}(\underline{\sigma})}{d \mu^{2}}<0
$$

Since $\operatorname{Pr}(\bar{\sigma})=\nu(1-\mu)+(1-\nu) \mu, \operatorname{Pr}(\underline{\sigma})=\nu \mu+(1-\mu)(1-\nu)$ and $\mathrm{E} \bar{e}=\bar{e}(\underline{\sigma}) \operatorname{Pr}(\underline{\sigma})+\bar{e}(\bar{\sigma}) \operatorname{Pr}(\bar{\sigma})$, we obtain

$$
\frac{d \mathrm{E} \bar{e}}{d \mu}<0, \quad \frac{d^{2} \mathrm{E} \bar{e}}{d \mu^{2}}<0
$$
}



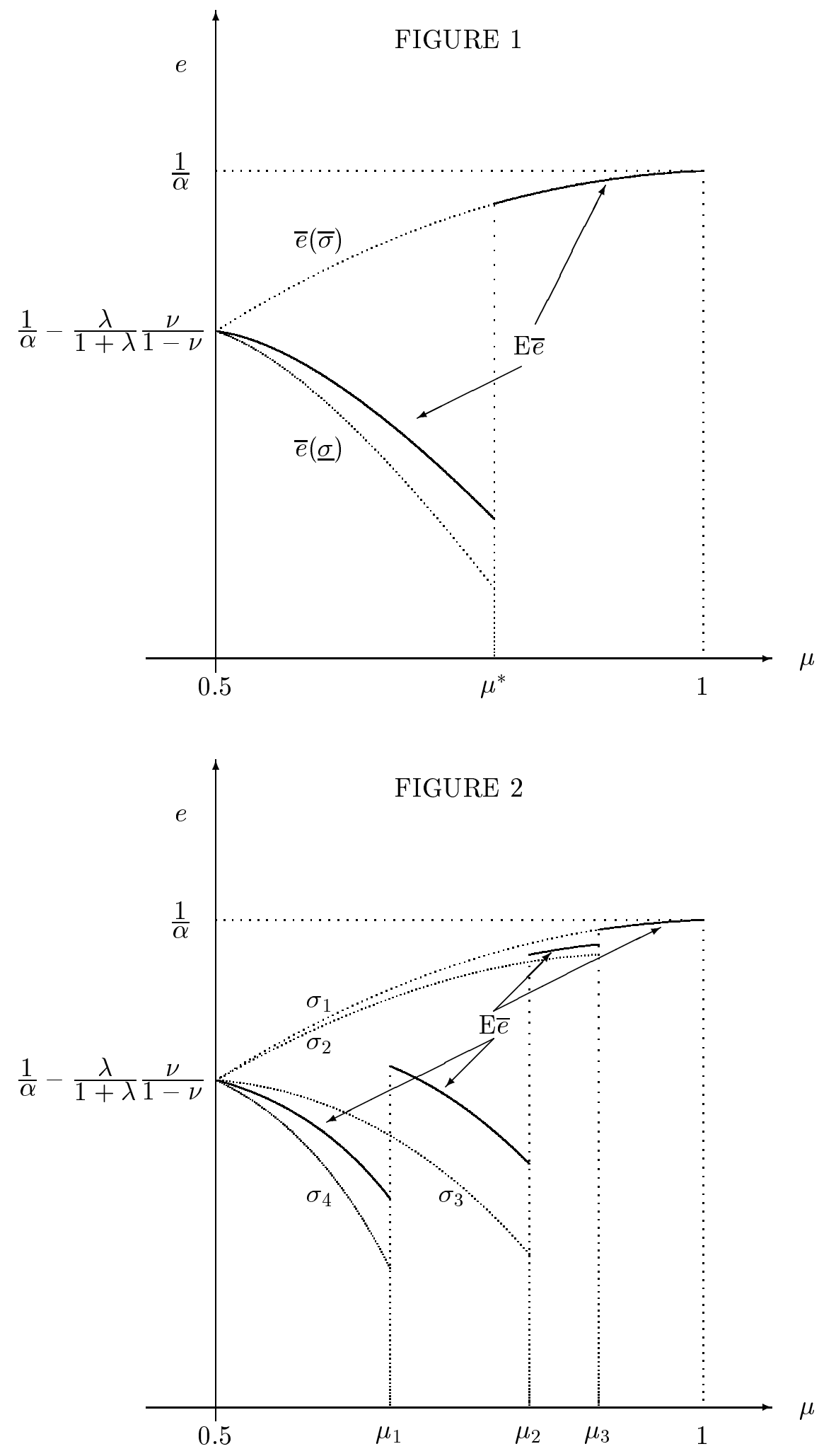
Case 2: The true type is discovered with probability $\xi$.

We now consider another example where the regulator discovers the true type of the firm with probability $\xi$ and nothing with probability $1-\xi .{ }^{10}$ This case refers to the possibility that a benchmarking study the regulator can conduct will reveal either the true efficiency of the firm (with probability $\xi$ ) or nothing useful (with probability $1-\xi$ ). The uninformative signal is like a signal $\sigma_{1}$ such that $\operatorname{Pr}\left(\sigma_{1} \mid \underline{\beta}\right)=\operatorname{Pr}\left(\sigma_{1} \mid \bar{\beta}\right)=1-\xi$. Observing $\sigma_{1}$ gives no information to the regulator and the power of incentives is unchanged. The favorable signal $\sigma_{2}$ is such that $\operatorname{Pr}\left(\sigma_{2} \mid \underline{\beta}\right)=\xi$ and $\operatorname{Pr}\left(\sigma_{2} \mid \bar{\beta}\right)=0$. Observing $\sigma_{2}$, we know for sure that the firm is of the good type: effort is efficient and no rent is captured by the firm. The unfavorable signal $\sigma_{3}$ is such that $\operatorname{Pr}\left(\sigma_{3} \mid \underline{\beta}\right)=0$ and $\operatorname{Pr}\left(\sigma_{3} \mid \bar{\beta}\right)=\xi$. Observing $\sigma_{3}$, the regulator knows for sure that he is facing a bad type firm: effort is efficient and no rent is left to the firm. Globally, the expected effort of the bad type (conditionally on being used) increases with $\xi$ : either there is no change, if $\sigma_{1}$ is observed, or $\bar{e}=1$ if $\sigma_{3}$ is observed. We are indeed in the special case of Proposition 2 .

Case 3: Only good type firms are discovered.

If only good firms can be identified following the benchmarking study, then $\operatorname{Pr}\left(\sigma_{1} \mid \underline{\beta}\right)=1-\xi$, $\operatorname{Pr}\left(\sigma_{1} \mid \bar{\beta}\right)=1, \operatorname{Pr}\left(\sigma_{2} \mid \underline{\beta}\right)=\xi, \operatorname{Pr}\left(\sigma_{2} \mid \bar{\beta}\right)=0$, and $\operatorname{Pr}\left(\sigma_{3} \mid \underline{\beta}\right)=\operatorname{Pr}\left(\sigma_{3} \mid \bar{\beta}\right)=0$. If the study reveals no new information, then it is an unfavorable signal since

$$
\hat{\nu}=\frac{\nu(1-\xi)}{1-\nu \xi}<\nu
$$

and incentives increase.

Case 4: Only bad type firms are discovered.

If only bad type firms can be discovered, then $\operatorname{Pr}\left(\sigma_{1} \mid \underline{\beta}\right)=1, \operatorname{Pr}\left(\sigma_{1} \mid \bar{\beta}\right)=1-\xi \cdot \operatorname{Pr}\left(\sigma_{2} \mid \underline{\beta}\right)=$ $\operatorname{Pr}\left(\sigma_{2} \mid \bar{\beta}\right)=0, \operatorname{Pr}\left(\sigma_{3} \mid \underline{\beta}\right)=0, \operatorname{Pr}\left(\sigma_{3} \mid \bar{\beta}\right)=\xi$, The power of incentives increases when a bad type firm is observed. When the type of the firm is not observed, it is a favorable signal. As long as $\hat{\nu}=\frac{\nu}{1-(1-\nu) \xi}<\nu^{*}$, both types of firm are kept and we are in the case of Proposition 1 and incentives decrease. If $\hat{\nu}>\nu^{*}$, we are in the case of Proposition 2 and incentives increase.

\footnotetext{
${ }^{10}$ As in Tirole (1986).
} 


\subsection{The general equilibrium effect}

To this point, we considered the value of $\lambda$ as given. But this value is the shadow price of the government budget constraint and therefore will in general vary with the level of expenditures. We consider in this section the general equilibrium effect of an improvement of information on the power of incentives taking into account the induced change in $\lambda$. As $\xi$ increases, the regulator has access to a better information structure and therefore can leave a smaller rent to the firm, thus reducing the pressures on the budget constraint and decreasing its shadow value. ${ }^{11}$ This enables him to provide more incentives. The interesting question is then whether this positive effect on incentives dominates the negative effect identified in Proposition 1. The following case shows that indeed the general equilibrium effect, through the change in the shadow price of the budget constraint may be strong enough to change the sign of the partial equilibrium effect.

Let us consider case 4 above where $\operatorname{Pr}(\sigma=\bar{\beta} \mid \bar{\beta})=\xi$ and $\sigma=\emptyset$ otherwise; we know that in this case incentives decrease with an increase in $\xi$ when the type of firm is not discovered, a favorable signal leading to $\hat{\nu}=\nu /[1-(1-\nu) \xi]>\nu$. The general welfare problem is

$$
\begin{gathered}
\max \quad E[(S-t)+(t-(\beta-e)-\psi(e))]=S-\nu(\underline{\beta}-\underline{e}+\psi(\underline{e}))-(1-\nu)(\bar{\beta}-\bar{e}+\psi(\bar{e})) \\
\text { subject to } E t=\nu(\underline{\beta}-\underline{e}+\psi(\underline{e}))+(1-\nu)(\bar{\beta}-\bar{e}+\psi(\bar{e}))+\nu \phi(\bar{e}) \leq K .
\end{gathered}
$$

We obtain

$$
\psi^{\prime}(\bar{e})=1-\frac{\lambda}{1+\lambda} \frac{\nu}{1-\nu} \frac{1}{1-\xi} \phi^{\prime}(\bar{e})
$$

that is, in the quadratic case (where $\psi(\bar{e})=\frac{1}{2} \alpha \bar{e}^{2}$ and $\phi(\bar{e})=\alpha\left(\bar{e}-\frac{1}{2}\right)$ )

$$
\bar{e}=\frac{1}{\alpha}-\frac{\lambda}{1+\lambda} \frac{\nu}{1-\nu} \frac{1}{1-\xi}
$$

where $\lambda$ is now the (endogenous) multiplier of the budget constraint. The budget constraint is

$$
\begin{aligned}
\nu[\underline{\beta}- & \left.e^{*}+\psi\left(e^{*}\right)\right]+\nu \phi(\bar{e}) \\
& +(1-\nu) \xi\left[\bar{\beta}-e^{*}+\psi\left(e^{*}\right)\right]+(1-\nu)(1-\xi)[\bar{\beta}-\bar{e}+\psi(\bar{e})]=K
\end{aligned}
$$

\footnotetext{
${ }^{11}$ The general equilibrium effect is related to the government global financial needs and becomes significant when some form of benchmarking or CCT is available and implemented for most if not all government activities or expenditures.
} 
that is, with a quadratic $\psi(e)$ function:

$$
E \beta+\left[(\nu+(1-\nu) \xi)\left(\frac{1}{2} \alpha e^{* 2}-e^{*}\right)\right]+\nu \alpha\left(\bar{e}-\frac{1}{2}\right)+(1-\nu)(1-\xi)\left(\frac{1}{2} \alpha \bar{e}^{2}-\bar{e}\right)=K .
$$

We obtain

$$
\begin{gathered}
\frac{d \bar{e}}{d \xi}=\frac{(1-\nu)\left(\frac{1}{2} \alpha \bar{e}^{2}-\bar{e}\right)-(1-\nu)\left(\frac{1}{2} \alpha e^{* 2}-e^{*}\right)}{\nu+(1-\nu)(1-\xi)(\bar{e}-1)}>0 \\
\frac{d \lambda}{d \xi}<0
\end{gathered}
$$

The partial analysis of case 4 above (considering $\lambda$ as fixed) led to $\frac{d \bar{e}}{d \bar{\xi}}<0$; we therefore conclude that the general equilibrium effect of $d \xi$ (through $\frac{d \lambda}{d \xi}<0$ ) is, in this case, of a sign different from that of the partial equilibrium effect of $d \xi$. The power of incentives increases because a larger $\xi$ implies on average a less stringent budget constraint. However, it is not always true that the general equilibrium effect will overcome the partial equilibrium effect. We illustrate this in Appendix 1.

A better information structure affects the regulator's welfare maximization problem and the level of incentives in three ways. It affects the expected cost of the project, ${ }^{12}$ the level of the rent $\phi(\bar{e})$ through its effect on the effort level $\bar{e}$, and the probability that this rent will be captured, that is, the posterior probability that the firm is a good type firm. Those effects modify the budget constraint and therefore its shadow value.

\section{THREAT OF LIQUIDATION AND INCENTIVES}

A different channel through which more intense competition is thought to affect incentives is the threat of bankruptcy or liquidation. For private non regulated firms, liquidation would follow from the decision of the financiers to refuse to refinance a firm with liquidity constraints because of its low expected payoff. For regulated or publicly owned firms or projects, "liquidation" would follow from a political decision to stop subsidizing the firm or project or to change the management team. For instance, it is reasonable to assume that politicians cannot commit not to use a much better alternative technology if and when it becomes available. Hence at the time

\footnotetext{
${ }^{12}$ In our context, there is no quantity effect since we are considering the realization of a given project. More generally, there would be a change in the production level too.
} 
of the contract, the current firm faces a probability of being dropped or liquidated. ${ }^{13}$ We are discussing a kind of auction which reduces the rent of the firm and induces higher effort as in Laffont and Tirole (1987). The lack of correlation between the firm's type and the alternative technology explains why the full extraction of the surplus, as in Crémer and McLean (1985), does not occur. We can suppose for instance that the alternative technology would allow the realization of the public project at some $\operatorname{cost} C$, a random variable with prior distribution function $G(C)$ and density $g(C)$. If $C<\psi(\bar{e})+\bar{\beta}-\bar{e}$, then the switch to the alternative technology would take place, that is, a new firm or management team would be chosen to realize the project and the current one would be "liquidated". Hence, the probability of no liquidation is given by $\operatorname{Pr}[C>\psi(\bar{e})+\bar{\beta}-\bar{e}]=1-G(\psi(\bar{e})+\bar{\beta}-\bar{e})$ an increasing function of $\bar{e}^{14}$ We want to characterize the impact of such a liquidation rule on the intensity of incentives.

For reasons of simplicity and specificity, we will assume that the liquidation rule takes the following reduced form: when the firm is of type $\bar{\beta}$, there is a probability of liquidation which increases with the cost of the firm and therefore decreases with the effort level $\bar{e}$. Let $1-k \delta(\bar{e})$ denote this probability of liquidation where $\delta^{\prime}(\bar{e})>0$ and $k$ is a positive parameter. Incentive compatibility implies that the rent of the efficient firm now takes the form $\underline{U}=k \delta(\bar{e}) \phi(\bar{e}) .{ }^{15}$ If we denote by $\bar{S}$ the social welfare when liquidation occurs, that is when the alternative technology is used to pursue the project, expected social welfare is

$$
\begin{aligned}
\nu[S & -(1+\lambda)(\psi(\underline{e})+\underline{\beta}-\underline{e})-\lambda k \delta(\bar{e}) \phi(\bar{e})] \\
& +(1-\nu) k \delta(\bar{e})[S-(1+\lambda)(\psi(\bar{e})+\bar{\beta}-\bar{e})]+(1-\nu)(1-k \delta(\bar{e})) \bar{S} .
\end{aligned}
$$

\footnotetext{
${ }^{13}$ Stricto sensu, one does not expect that a public quasi-monopoly firm such as a state-owned power generating firm, telecoms or rail or marine transportation firms would simply be shut down. But the management team could be replaced if it were perceived as inefficient and the firm could face significant restructuring, with downsizing and outsourcing, if its operating costs were deemed too high.

${ }^{14}$ The experience of the Compulsory Competitive Tendering (CCT) process in the U.K. is an interesting real example. Before offering a public service directly to the citizens, through a publicly owned Direct Service Organization (DSO), a municipal government must invite private firms to bid for the project or service together with the DSO who must act then as a separate entity. If a private firm outbids the municipal DSO, then it wins the contract and the DSO is "liquidated". If not, the DSO is awarded an incentive contract for the service or project. The U.K. experience shows that DSOs won about $70 \%$ of the contracts and were therefore "liquidated" with a probability of 0.3 .

${ }^{15}$ Choosing the contract $(\bar{t}, \bar{C})$, the efficient firm faces the risk of losing the contract to the alternative technology; it captures $\phi(\bar{e})$ with probability $k \delta(\bar{e})$.
} 
Maximizing we obtain (assuming concavity in $\bar{e}$ ):

$$
\begin{aligned}
\psi^{\prime}(\underline{e})= & 1 \\
\psi^{\prime}(\bar{e})=1- & \frac{\lambda}{1+\lambda} \frac{\nu}{1-\nu} \phi^{\prime}(\bar{e})-\frac{\lambda}{1+\lambda} \frac{\delta^{\prime}(\bar{e}) \phi(\bar{e})}{\delta(\bar{e})} \\
& \quad+\frac{\delta^{\prime}(\bar{e})}{(1+\lambda) \delta(\bar{e})}[S-(1+\lambda)(\psi(\bar{e})+\bar{\beta}-\bar{e})-\bar{S}] .
\end{aligned}
$$

A marginal increase in the threat of liquidation (increase of $k$ ) has no effect, because it has no effect on the rent extraction-efficiency trade-off (since the information rent decreases exactly as the gain from having the inefficient firm active decreases), and it has no effect on the rate of increase of the probability of liquidation $\delta^{\prime}(\bar{e}) / \delta(\bar{e})$.

Proposition 3: The power of incentives is insensitive to a marginal increase of the probability of liquidation, as long as the regulator's optimization program remains concave.

Note however that with a more general formulation $\delta(k, e)$, we would get results depending on the cross derivative $\frac{\partial^{2} \delta(k, e)}{\partial e \partial k}$.

\section{COMPETITION IN TALENT}

An alternative channel through which competition operates is that it increases the 'market' value of good agents in the private sector. It will then be necessary to offer higher payoffs to good type agents in the public sector in order to meet their participation constraint. This channel brings into focus the relationship between the public sector wage structure and the private sector one. There are good reasons why one may expect that the wage structure is more egalitarian in the public sector. One such reason is the redistribution objective of the government. In this context, public authorities act as if they were using a modified utilitarian social welfare function where a weight $\alpha^{*}<1$ is associated with the profit or informational rent of the good agent. This will lead to larger overall efficiency distortions in order to lower the less valuable informational rent. Using the social welfare function

$$
S-(1+\lambda)(t+\beta-e)+\alpha^{*}(t-\psi(e))
$$


that is,

$$
\nu\left(S-(1+\lambda)(\underline{\beta}-\underline{e}+\psi(\underline{e}))-\left(1+\lambda-\alpha^{*}\right) \phi(\bar{e})\right)+(1-\nu)(S-(1+\lambda)(\bar{\beta}-\bar{e}+\psi(\bar{e})))
$$

we obtain the first-order condition

$$
\nu\left(1+\lambda-\alpha^{*}\right) \phi^{\prime}(\bar{e})-(1-\nu)(1+\lambda)\left(\psi^{\prime}(\bar{e})-1\right)=0
$$

that is, for $\epsilon=1-\alpha^{*}$,

$$
\psi^{\prime}(\bar{e})=1-\frac{\nu}{1-\nu} \frac{\lambda+\epsilon}{1+\lambda} \psi^{\prime \prime}(\bar{e})
$$

implying, since $\epsilon>0$, a reduction in $\bar{e}$ and $\phi(\bar{e})$, that is, lower incentives and a smaller rent for good type agents.

The trade-off between efficiency and rent minimization is in a sense solved in favor of rent minimization: efficiency is lower, that is, incentives are weaker but the good types capture a smaller informational rent. In the private sector, the absence of a redistribution objective together with competitive pressures make the firms behave as if, in order to avoid being creamskimmed on the labor market, a utilitarian objective function with $\alpha^{* *}>\alpha^{*}$ were used and therefore bring out a solution more in line with efficiency: stronger incentives are implemented and larger rents are captured by the good type. As competition in the private sector increases, $\alpha^{* *}$ increases, generating more intense competition for the public sector which is implicitly led to increase the value of $\alpha^{*}$ in order to avoid the loss of the more capable, good type agents. Hence, although there may not be a perfect alignment of incentives between the public and private sectors, the emergence of a more competitive environment would affect both.

In our model this competition in talent phenomenon can be modeled as an increase in the reservation utility level of a good type manager which was so far normalized at zero. Let $\underline{U}_{0}$ be this new reservation utility level. The maximization program of the regulator (MP) is as given above except for the participation constraint of the good type which becomes

$$
\underline{U} \geq \underline{U}_{0}
$$

There are four regions of interest, as represented in Figure 3. 


\section{FIGURE 3}

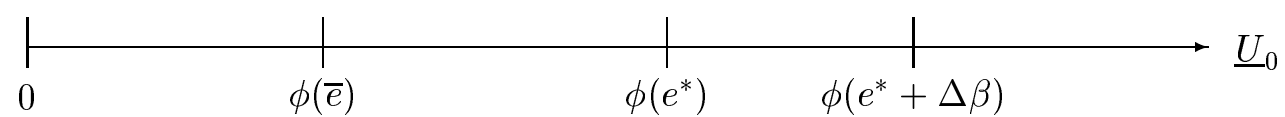

As long as $\underline{U}_{0} \leq \phi(\bar{e})$, with $\bar{e}$ defined by (6) and obtained for $\underline{U}_{0}=0$, the optimal regulation is unchanged since the information rent is large enough to satisfy the new participation constraint of the good type agent. However, when $\underline{U}_{0}$ becomes larger than this information rent $\phi(\bar{e})$ but is still less than $\phi\left(e^{*}\right)$, the relevant binding constraints become the two IR constraints and the incentive constraint of the bad type. Effort level $\underline{e}$ is still defined by $\psi^{\prime}(\underline{e})=1$ and $\bar{e}$ is simply defined by $\phi(\bar{e})=\underline{U}_{0}$. So the effort level of the bad type is increased (incentives increase) in order to create a sufficiently large rent (but not larger than necessary) for the good type to stay in the public or regulated firm.

When $\underline{U}_{0}$ becomes larger than $\phi\left(e^{*}\right)$ but still less than $\phi\left(e^{*}+\Delta \beta\right)$, there is no point in increasing further $\bar{e}$ which has reached the efficient level $e^{*}$. Only the IR constraints are binding and both effort levels are efficient.

Finally, if $\underline{U}_{0}$ becomes larger than $\phi\left(e^{*}+\Delta \beta\right)$, the incentive constraint of the bad type agent becomes binding. A rent must be given up to the bad type. To mitigate this rent, the effort level $\underline{e}$ is increased beyond the efficient level. It is defined by

$$
\psi^{\prime}(\underline{e})=1+\frac{\nu}{1-\nu} \frac{\lambda}{1+\lambda} \phi^{\prime}(\underline{e}+\Delta \beta)
$$

Competition from the unregulated sector obliges the public sector to select incentive schemes which are even more powerful than the efficient ones to keep the good type within the public sector.

\section{Proposition 4: Competition in talent always favors stronger incentives.}

\section{A MORE COMPETITIVE ENVIRONMENT}

Another meaning of increased competition is that the unregulated (private) sector which produces goods that are substitutes for the regulated sector good has become more competitive. 
A more competitive unregulated sector either produces at lower cost than before or produces goods which have become better substitutes. We consider the effect of those changes on the power of incentives in the regulated sector.

Let us assume that the social value of production from both sectors is now given by

$$
S\left(q_{1}+q_{2}\right)+\theta q_{1} q_{2}
$$

where $q_{1}$ is the variable output of the regulated sector and $q_{2}$ is the output of the competitive sector and where $\theta \geq 0$ is a measure of how complementary the products of the two sectors are. As $\theta$ increases [decreases], the goods become more complementary [substitute] ${ }^{16}$ and the demand of each good increases [decreases] as usual.

Assuming that $C\left(q_{2}\right)=c q_{2}$, that the output of the regulated firm is "sold" at its marginal value level, that the proceeds go into the public budget and are therefore generating an extra value of $\lambda p_{1}\left(q_{1}, q_{2}\right) q_{1}$, and that the benevolent regulator cares about total welfare, we can write the regulator's objective function as

$$
S\left(q_{1}+q_{2}\right)+\theta q_{1} q_{2}+U-(1+\lambda)\left(t+(\beta-e) q_{1}\right)-c q_{2}+\lambda p_{1}\left(q_{1}, q_{2}\right) q_{1}
$$

where $U=t-\psi(e)$ is the regulated firm's utility. Under full information, the regulator wants the firm to exert the optimal level of effort $e^{*}$ characterized by $\psi^{\prime}\left(e^{*}\right)=q_{1}$ for both types of the regulated firm while operating a transfer $t$ leaving no rent to the regulated firm, $\underline{U}=\bar{U}=0$.

We assume that $\beta \in\{\underline{\beta}, \bar{\beta}\}$ is private information of the firm while the private sector technology, that is $c$, is common knowledge. This simplifying assumption can be justified by the yardstick competition in the private sector which generates a perfect informative signal making $c$ known to the regulator. The regulator maximizes the expected social welfare under the usual individual rationality and incentive compatibility constraints of both types and balances efficiency and rents by determining the output and effort levels of the regulated sector as a function of $\beta$. We obtain (see Appendix 2): $\psi^{\prime}(\underline{e})=\underline{q}_{1}$ and $\psi^{\prime}(\bar{e})=\bar{q}_{1}-\frac{\lambda}{1+\lambda} \frac{\nu}{1-\nu} \phi^{\prime}(\bar{e})<\bar{q}_{1}$. We can model an increase in competitive pressures by making the private sector more efficient, that is reducing $c$, or by making the two goods better substitutes, that is reducing $\theta$.

\footnotetext{
${ }^{16}$ The cross derivative of social welfare with respect to $q_{1}$ and $q_{2}$ is $S^{\prime \prime}+\theta$; if $S^{\prime \prime}+\theta>[<] 0$, the goods are demand complements [demand substitutes].
} 


\subsection{The reduction in private sector costs}

Let us first consider a reduction in $c$. We can show (see Appendix 2) that, whatever the efficiency of the regulated sector, a reduction in production cost $c$ increases the output of the private sector but may increase or decrease the production of the regulated sector. Let us assume that the products are demand substitutes, that is $S^{\prime \prime}+\theta<0 .{ }^{17}$ If the products are demand substitutes and strategic substitutes, ${ }^{18}$ then the production of the regulated sector decreases when $c$ decreases, implying a reduction in incentives (no change in effort $\underline{e}$ but a reduction in effort $\bar{e}$ ) and in the rent of the efficient type firm. If the products are demand substitutes and strategic complements with $\lambda$ large enough, then the production of the regulated sector increases when $c$ decreases, implying an increase in incentives (no change in effort $\underline{e}$ but an increase in effort $\bar{e}$ ) and in the rent of the efficient type firm.

The intensity of incentives, measured by ${ }^{19}$

$$
k=\frac{\psi^{\prime}(e)}{C_{e}}=\frac{\psi^{\prime}(e)}{q_{1}},
$$

remains constant (at $k=1$ ) for the efficient type but may increase or decrease for the inefficient type, depending on the value of $\lambda$. For $\lambda$ small, the effect of a reduction in $c$ on the intensity of incentives is of the same sign as the effect on the production level of the regulated sector. But for $\lambda$ sufficiently large, we can have an opposite sign: ${ }^{20}$ if the products are demand substitutes but strategic complements and the value of $\lambda$ is large enough, a reduction in the marginal cost $c$ increases both production and effort in the public sector, but nevertheless the intensity of incentives decreases, as shown in Appendix 2.

Proposition 5: If the regulated product $q_{1}$ and the private sector unregulated product $q_{2}$ are strategic substitutes, then a reduction in marginal cost c reduces incentives for the regulated

\footnotetext{
${ }^{17}$ The reader can adapt the analysis to the case of demand complements.

${ }^{18}$ The products are strategic substitutes [complements] if the marginal social revenue from good $i$ decreases [increases] with the production of good $j$, that is, if $S^{\prime \prime \prime} q_{i}+S^{\prime \prime}+\theta<[>] 0$. If the goods are demand substitutes, we have $S^{\prime \prime}+\theta<0$; hence whether the goods are strategic substitutes or strategic complements depends on the sign and magnitude of $S^{\prime \prime \prime} q_{i}$ relative to $S^{\prime \prime}+\theta$. See Appendix 2 for details.

${ }^{19}$ The intensity of incentives corresponds to that part $k$ of the realized cost which is borne by the firm at the margin: if $U=t-k C(\beta, e, q)-\psi(e)=t-k(\beta-e) q-\psi(e)$, then $U_{e}=k q-\psi^{\prime}(e)=0 \operatorname{implies} k=\frac{\psi^{\prime}(e)}{q} \in(0,1]$.

${ }^{20}$ Unless $\phi^{\prime \prime}=0$, as for the quadratic case $\psi(e)=\frac{1}{2} \alpha e^{2}$.
} 
firm. If the products are strategic complements and $\lambda$ is large enough, then a reduction in $c$ increases incentives for the regulated firm.

So if greater competition means lower cost competitors, strategic complementarity and a high social cost of public funds are the keys to greater production of the public sector and therefore to greater effort and larger rents. When $\lambda$ is large but not too large, greater effort is equivalent to higher power of incentives. ${ }^{21}$

\subsection{Improved substitutes for the regulated firm's product}

Let us now consider an increase in substitutability, that is, a reduction in $\theta$. We can show (see Appendix 2) for both $\underline{\beta}$ and $\bar{\beta}$ that the effect of a change in $\theta$ on the production level and effort level in the public sector are of the same sign. If the products are strategic complements with $\lambda$ large enough, then the product levels $q_{1}$ and $q_{2}$ as well as the effort level $e$ are all reduced as $\theta$ decreases. Indeed, a reduction of $\theta$ increases substitution but also reduces the value of both commodities to consumers. If on the other hand the products are strong enough strategic substitutes, the substitution effect may dominate and $q_{1}$ may increase as well as $\bar{e}$.

Proposition 6: If the regulated product $q_{1}$ and the private sector unregulated product $q_{2}$ are strategic complements with $\lambda$ large enough, then the incentives of the regulated firm decrease with an increase in the degree of substitution. If the products are strong enough strategic substitutes, then the incentives of the regulated firm increase with the degree of substitution.

When more competition means better substitutability between the public and private sectors products (and an increase in their global demand), then strategic substitutability is the key to higher production, effort and rent in the public sector (unless the social cost of public fund is low).

\footnotetext{
${ }^{21}$ We need

$$
\lambda>\max \left\{\frac{-\left(S^{\prime \prime}+\theta\right)}{S^{\prime \prime}+\theta+S^{\prime \prime \prime} \bar{q}_{1}} \quad \text { and } \quad \frac{\psi^{\prime \prime}}{\psi^{\prime \prime}+\frac{\lambda}{1+\lambda} \frac{\nu}{1-\nu} \phi^{\prime \prime}}>\frac{\psi^{\prime}}{\bar{q}_{1}}\right.
$$
}


It is important to stress here that we have simplified the analysis by taking the particular cost function $C=(\beta-e) q$ which yields the first order condition of the bad type

$$
\psi^{\prime}(\bar{e})=\bar{q}_{1}-\frac{\lambda}{1+\lambda} \frac{\nu}{1-\nu} \phi^{\prime}(\bar{e})
$$

from which the effects of competition can be tracked. Clearly these effects work through $\bar{q}_{1}$ by changing the social profitability of effort. With a more general cost function satisfying the incentive dichotomy property $C=C\left(\Phi(\beta, e), q_{1}\right)$ the channel would remain similar, $\frac{\partial C}{\partial e}$ replacing $q_{1}$. If we drop the incentive dichotomy assumption, competition can affect more directly the incentive constraint and the rent. The marginal rent is now given by $\phi^{\prime}(e) E_{\beta}(\beta, e, q)$ where $E(\beta, e, q)$ is the solution in $e$ of $\bar{C}=C(\beta, e, q)$, that is, the effort level which enables a firm of type $\beta$ to produce $q$ with a cost of $\bar{C}$. Furthermore, the pricing equation requires an incentive correction and the effect of a change in the production level, due to increased competition, on the effort level is obtained by differentiating the whole system

$$
\begin{gathered}
\frac{\bar{p}_{1}-C_{q_{1}}}{\bar{p}_{1}}=\frac{\lambda}{1+\lambda} \frac{1}{\hat{\eta}_{1}}+I \\
\psi^{\prime}(\bar{e})=-C_{e}(\beta, e, q)-\frac{\lambda}{1+\lambda} \frac{\nu}{1-\nu} \phi^{\prime} E_{\beta}(\beta, e, q) .
\end{gathered}
$$

\section{CONCLUSION}

We characterized the effects of stronger competitive pressures on public sector incentives, more precisely on the level of incentives in an optimally regulated sector. Maybe contrary to conventional wisdom or a first intuition, greater competition does not always call for higher incentives.

We identified different channels through which competition affects the power of incentives. First, we looked at the information channel, namely the idea that more competition provides the principal, the regulator, with information about the agent, the regulated sector. We showed in propositions 1 and 2 that the effect of better information on the power of incentives may be positive or negative. If the quality of the competition signal is sufficiently high to induce the regulator to drop the public project following a favorable signal, the power of incentives increases; if it is not, then the expected power of incentives decreases if the effort level is a concave function 
of the hazard rate; the latter is verified in two important particular cases, when the cost of effort is quadratic and when the social cost of public funds $\lambda$ is small. Moreover, we characterized the general equilibrium effect of a better information structure, considering $\lambda$ as endogenous, and we showed that its sign may be different from that of the partial equilibrium effect. The main reason for the ambiguous results is that greater information provided by a more competitive environment may alter the desirable trade-off between efficiency and rent extraction towards less rent extraction on average. However, when the competition signal is better, that is, becomes very informative, the expected result obtains.

Second, we looked at the threat of liquidation effect and we showed that the power of incentives is insensitive to local increases of this threat. Third, we analyzed the competition in talent effect and we showed that this effect increases also the power of incentives.

Fourth, we considered a model of a more competitive environment and we showed (i) that the effect of a cost reduction in the competitive unregulated sector, producing a substitute product to that of the regulated firm, on the power of incentives is negative [positive] when the products are strategic substitutes [strategic complements and $\lambda$ is large], and (ii) that the effect of an increase in substitutability between the products is positive [negative] if the degree of demand substitution is strong enough [if the products are strategic complements and $\lambda$ is large]. The main reason for the ambiguous result is that the desirable change in the power of incentives is related to the level of activity of the regulated firm and to the interaction between effort and production level in the cost function. Depending on the nature and strength of the substitutability or complementarity between the regulated product and the goods produced by the unregulated competitors, greater competitive pressures from the latter may call for a shrinkage or an expansion of the public sector, and that determines to a large extent the desirable change in the power of incentives.

A next step in the analysis would be to recognize that, for political economy reasons, regulation is not optimized and study to which extent the increase in competition disciplines the regulators. ${ }^{22}$

\footnotetext{
${ }^{22}$ This would require an explicit political economy model as in Boyer and Laffont (1999) or an explicit hierarchical model with incomplete contracts as in Laffont and N'Guessan (1999).
} 


\section{Appendix 1}

\section{A Non-Reversing General Equilibrium Effect}

We consider the general equilibrium effect for the following information structure of case 1 . We have

$$
\begin{aligned}
& \bar{e}(\underline{\sigma})=\frac{1}{\alpha}-\frac{\lambda}{1+\lambda} \frac{\nu}{1-\nu} \frac{\mu}{1-\mu} \\
& \bar{e}(\bar{\sigma})=\frac{1}{\alpha}-\frac{\lambda}{1+\lambda} \frac{\nu}{1-\nu} \frac{1-\mu}{\mu},
\end{aligned}
$$

hence $\bar{e}(\bar{\sigma}) \geq \bar{e}(\underline{\sigma})$, and the budget constraint

$$
\begin{aligned}
& \nu \mu\left[\underline{\beta}-e^{*}+\frac{1}{2} \alpha e^{* 2}+\alpha\left(\bar{e}(\underline{\sigma})-\frac{1}{2}\right)\right]+(1-\nu)(1-\mu)\left[\bar{\beta}-\bar{e}(\underline{\sigma})+\frac{1}{2} \alpha(\bar{e}(\underline{\sigma}))^{2}\right] \\
& +\nu(1-\mu)\left[\underline{\beta}-e^{*}+\frac{1}{2} \alpha e^{* 2}+\alpha\left(\bar{e}(\bar{\sigma})-\frac{1}{2}\right)\right]+(1-\nu) \mu\left[\bar{\beta}-\bar{e}(\bar{\sigma})+\frac{1}{2} \alpha(\bar{e}(\bar{\sigma}))^{2}\right]=K
\end{aligned}
$$

Totally differentiating the system of equations $(17),(18)$ and (19) with respect to $\bar{e}(\underline{\sigma}), \bar{e}(\bar{\sigma}), \lambda$ and $\mu$, we obtain

\begin{tabular}{ccccc}
\hline$d \bar{e}(\underline{\sigma})$ & $d \bar{e}(\bar{\sigma})$ & $d \lambda$ & & $d \mu$ \\
& & & & \\
1 & 0 & $B_{1}$ & & $C_{1}$ \\
0 & 1 & $B_{2}$ & $=$ & $C_{2}$ \\
$A_{1}$ & $A_{2}$ & 0 & & $\Gamma$ \\
& & & & \\
\hline
\end{tabular}

where $\Gamma=\nu\left[\alpha\left(\bar{e}(\underline{\sigma})-\frac{1}{2}\right)-\alpha\left(\bar{e}(\bar{\sigma})-\frac{1}{2}\right)\right]+(1-\nu)\left[\left(\frac{1}{2} \alpha(\bar{e}(\bar{\sigma}))^{2}-\bar{e}(\bar{\sigma})\right)-\left(\frac{1}{2} \alpha(\bar{e}(\underline{\sigma}))^{2}-\bar{e}(\underline{\sigma})\right)\right]<0$, with $\bar{e}(\underline{\sigma})$ and $\bar{e}(\bar{\sigma})$ given by (17) and (18), and

$$
\begin{gathered}
B_{1}=\frac{1}{(1+\lambda)^{2}} \frac{\nu}{1-\nu} \frac{\mu}{1-\mu}>0, \quad B_{2}=\frac{1}{(1+\lambda)^{2}} \frac{\nu}{1-\nu} \frac{1-\mu}{\mu}>0 \\
C_{1}=-\frac{\lambda}{1+\lambda} \frac{\nu}{1-\nu} \frac{1}{(1-\mu)^{2}}<0, \quad C_{2}=\frac{\lambda}{1+\lambda} \frac{\nu}{1-\nu} \frac{1}{\mu^{2}}>0 \\
A_{1}=-\nu \mu \frac{1}{1+\lambda}<0, \quad A_{2}=-\nu(1-\mu) \frac{1}{1+\lambda}<0
\end{gathered}
$$

with the determinant $\Delta=-A_{2} B_{2}-A_{1} B_{1}>0$. Observing that $A_{1}<A_{2}<0,\left|C_{1}\right|>\left|C_{2}\right|$ and $B_{1}>B_{2}>0$, we obtain

$$
\frac{d \lambda}{d \mu} \propto+\Gamma-C_{2} A_{2}-C_{1} A_{1}<0
$$




$$
\begin{aligned}
& \frac{d \bar{e}(\underline{\sigma})}{d \mu} \propto-\Gamma B_{1}-A_{2} C_{1} B_{2}+A_{2} B_{1} C_{2} \geq 0 \\
& \frac{d \bar{e}(\bar{\sigma})}{d \mu} \propto-\Gamma B_{2}+A_{2} C_{1} B_{2}-A_{1} B_{1} C_{2}>0 .
\end{aligned}
$$

The sign of $\frac{d \bar{e}(\underline{\sigma})}{d \mu}$ may be positive or negative. It depends on two effects: the partial equilibrium effect ( $\lambda$ fixed) and the general equilibrium effect through $\frac{d \lambda}{d \mu}<0$, namely

$$
\left.\frac{d \bar{e}(\underline{\sigma})}{d \mu} \propto \frac{\partial \bar{e}(\underline{\sigma})}{\partial \mu}\right|_{d \lambda=0}+\frac{B_{1}}{B_{2}}\left(\frac{\Gamma}{A_{2}}-C_{2}\right)
$$

where the first term is negative [equal to $C_{1}<0$ ] and the second term is of the sign of

$$
-\Gamma+A_{2} C_{2}=-\Gamma-\frac{\lambda}{(1+\lambda)^{2}} \frac{\nu^{2}}{1-\nu} \frac{1-\mu}{\mu^{2}} .
$$

Indeed, for $\alpha=\frac{2}{9}, \lambda=\frac{1}{3}, \nu=\frac{3}{4}$, we have $\frac{d \bar{e}(\underline{\sigma})}{d \mu}=-1.31$ if $\mu=\frac{2}{3}$, and $\frac{d \bar{e}(\underline{\sigma})}{d \mu}=+0.49$ if $\mu=\frac{3}{4}$.

\section{Appendix 2}

\section{Increases in Competitive Pressures from the Private Sector}

We wish to maximize social welfare

$$
\begin{gathered}
W=\nu\left[S\left(\underline{q}_{1}+\underline{q}_{2}\right)+\theta \underline{q}_{1} \underline{q}_{2}-(1+\lambda)\left(\psi(\underline{e})+(\underline{\beta}-\underline{e}) \underline{q}_{1}\right)\right. \\
\left.-c \underline{q}_{2}+\lambda p_{1}\left(\underline{q}_{1}, \underline{q}_{2}\right) \underline{q}_{1}-\lambda \underline{U}\right] \\
+(1-\nu)\left[S\left(\bar{q}_{1}+\bar{q}_{2}\right)+\theta \bar{q}_{1} \bar{q}_{2}-(1+\lambda)\left(\psi(\bar{e})+(\bar{\beta}-\bar{e}) \bar{q}_{1}\right)\right. \\
\left.-c \bar{q}_{2}+\lambda p_{1}\left(\bar{q}_{1}, \bar{q}_{2}\right) \bar{q}_{1}-\lambda \bar{U}\right]
\end{gathered}
$$

subject to

$$
\begin{array}{ll}
\underline{I R}: & \underline{U} \geq 0 \\
\overline{I R}: & \bar{U} \geq 0 \\
\underline{I C}: & \underline{t}-\psi(\underline{e}) \geq \bar{t}-\psi(\bar{e})+\phi(\bar{e}) \\
\overline{I C}: & \bar{t}-\psi(\bar{e}) \geq \underline{t}-\psi(\underline{e}-\Delta \beta) \\
\text { with } & \phi(e)=\psi(e)-\psi(e-\Delta \beta)
\end{array}
$$


Totally differentiating the relevant systems of equations, we find the effect of a change in $c$ :

$$
\begin{aligned}
\frac{d \underline{q}_{1}}{d c} & =\frac{1}{D} \psi^{\prime \prime}\left(S^{\prime \prime}+\theta+\lambda\left[\frac{\partial^{2} p_{1}}{\partial q_{1} \partial q_{2}} q_{1}+\frac{\partial p_{1}}{\partial q_{2}}\right]\right) \\
\frac{d \underline{q}_{2}}{d c} & =\frac{1}{D}\left[-\psi^{\prime \prime}\left(S^{\prime \prime}+\lambda\left[\frac{\partial^{2} p_{1}}{\partial q_{1}^{2}}+2 \frac{\partial p_{1}}{\partial q_{1}}\right]\right)-(1+\lambda)\right]<0 \\
\frac{d \underline{e}}{d c} & =\frac{1}{D}\left(S^{\prime \prime}+\theta+\lambda\left(\frac{\partial^{2} p_{1}}{\partial q_{1} \partial q_{2}} q_{1}+\frac{\partial p_{1}}{\partial q_{2}}\right)\right) \\
\frac{d \bar{q}_{1}}{d c} & =-\frac{1}{D}\left[\left(-\psi^{\prime \prime}-\frac{\lambda}{1+\lambda} \frac{\nu}{1+\nu} \phi^{\prime \prime}\right)\left(S^{\prime \prime}+\theta+\lambda\left[\frac{\partial^{2} p_{1}}{\partial q_{1} \partial q_{2}} q_{1}+\frac{\partial p_{1}}{\partial q_{2}}\right]\right)\right] \\
\frac{d \bar{q}_{2}}{d c} & =\frac{1}{D}\left[\left(-\psi^{\prime \prime}-\frac{\lambda}{1+\lambda} \frac{\nu}{1+\nu} \phi^{\prime \prime}\right)\left(S^{\prime \prime}+\lambda\left[\frac{\partial^{2} p_{1}}{\partial q_{1}^{2}}+2 \frac{\partial p_{1}}{\partial q_{1}}\right]\right)-(1+\lambda)\right]<0 \\
\frac{d \bar{e}}{d c} & =\frac{1}{D}\left(S^{\prime \prime}+\theta+\lambda\left[\frac{\partial^{2} p_{1}}{\partial q_{1} \partial q_{2}} q_{1}+\frac{\partial p_{1}}{\partial q_{2}}\right]\right)
\end{aligned}
$$

leading to

$$
\begin{aligned}
& \frac{d q_{2}}{d c}<0 \\
\operatorname{SIGN}\left(\frac{d q_{1}}{d c}\right)=\operatorname{SIGN}\left(\frac{d e}{d c}\right)= & \operatorname{SIGN}\left[-\left(S^{\prime \prime}+\theta+\lambda\left[\frac{\partial^{2} p_{1}}{\partial q_{1} \partial q_{2}} q_{1}+\frac{\partial p_{1}}{\partial q_{2}}\right]\right)\right] \\
= & \operatorname{SIGN}\left[-\left(S^{\prime \prime}+\theta+\lambda \frac{\partial M R\left(q_{1}\right)}{\partial q_{2}}\right)\right] \\
= & \operatorname{SIgN}\left[-\left(S^{\prime \prime}+\theta+\lambda\left[S^{\prime \prime \prime} q_{1}+S^{\prime \prime}+\theta\right]\right)\right] \\
= & \operatorname{SIgN}\left[-(1+\lambda)\left(S^{\prime \prime}+\theta\right)-\lambda S^{\prime \prime \prime} q_{1}\right]
\end{aligned}
$$

As for the intensity of incentives $k$, we have

$$
\frac{d k}{d c}=\frac{1}{q_{1}} \psi^{\prime \prime} \frac{d e}{d c}+\psi^{\prime}\left(-\frac{1}{q_{1}^{2}}\right) \frac{d q_{1}}{d c} .
$$

Since $\frac{d e}{d c} \psi^{\prime \prime}=\frac{d \underline{q}_{1}}{d c}$ and $\frac{d \bar{e}}{d c}\left[\psi^{\prime \prime}+\frac{\nu}{1-\nu} \frac{\lambda}{1+\lambda} \phi^{\prime \prime}\right]=\frac{d \bar{q}_{1}}{d c}$, we obtain

$$
\begin{gathered}
\frac{d \underline{k}}{d c}=\frac{1}{\underline{q}_{1}}\left[1-\frac{\psi^{\prime}(\underline{e})}{\underline{q}_{1}}\right] \frac{d \underline{q}_{1}}{d c}=0 \\
\frac{d \bar{k}}{d c}=\frac{1}{\bar{q}_{1}}\left[\frac{\psi^{\prime \prime}(\bar{e})}{\psi^{\prime \prime}(\bar{e})+\frac{\nu}{1-\nu} \frac{\lambda}{1+\lambda} \phi^{\prime \prime}(\bar{e})}-\frac{\psi^{\prime}(\bar{e})}{\bar{q}_{1}}\right] \frac{d \bar{q}_{1}}{d c} .
\end{gathered}
$$


The intensity of incentives for the good type remains constant but, for $\lambda$ sufficiently large and $\phi^{\prime \prime} \neq 0$,

$$
\operatorname{SIGN}\left(\frac{d \bar{k}}{d c}\right)=-\operatorname{SIGN}\left(\frac{d \bar{q}_{1}}{d c}\right) .
$$

Regarding the effect of a change in $\theta$, we find:

$$
\begin{aligned}
& \frac{d \underline{q}_{1}}{d \theta}=\frac{\psi^{\prime \prime}}{D}\left[-q_{1}\left(S^{\prime \prime}+\theta+\lambda\left[\frac{\partial^{2} p_{1}}{\partial q_{1} \partial q_{2}} q_{1}+\frac{\partial p_{1}}{\partial q_{2}}\right]\right)+q_{2}\left(S^{\prime \prime}+\lambda\left[\frac{\partial^{2} p_{1}}{\partial q_{2}^{2}} q_{1}\right]\right)\right] \\
& \frac{d \underline{q}_{2}}{d \theta}=\frac{1}{D}\left[\psi^{\prime \prime}\left(S^{\prime \prime}+\lambda\left[\frac{\partial^{2} p_{1}}{\partial q_{1}^{2}}+2 \frac{\partial p_{1}}{\partial q_{1}}\right]\right) q_{1}-\psi^{\prime \prime}\left(S^{\prime \prime}+\theta+\lambda\left[\frac{\partial^{2} p_{1}}{\partial q_{1} \partial q_{2}} q_{1}+\frac{\partial p_{1}}{\partial q_{2}}\right]\right) q_{2}+(1+\lambda) q_{1}\right] \\
& =\frac{1}{D}\left[-q_{1}\left[\left(S^{\prime \prime}+\lambda\left[\frac{\partial^{2} p_{1}}{\partial q_{1}^{2}}+2 \frac{\partial p_{1}}{\partial q_{1}}\right]\right)\left(-\psi^{\prime \prime}\right)-(1+\lambda)\right]+q_{2}\left(S^{\prime \prime}+\theta+\lambda\left[\frac{\partial^{2} p_{1}}{\partial q_{1} \partial q_{2}} q_{1}+\frac{\partial p_{1}}{\partial q_{2}}\right]\right)\left(-\psi^{\prime \prime}\right)\right] \\
& \frac{d \underline{e}}{d \theta}=\frac{1}{D}\left[-q_{1}\left(S^{\prime \prime}+\theta+\lambda\left[\frac{\partial^{2} p_{1}}{\partial q_{1} \partial q_{2}} q_{1}+\frac{\partial p_{1}}{\partial q_{2}}\right]\right)+q_{2}\left(S^{\prime \prime}+\lambda\left[\frac{\partial^{2} p_{1}}{\partial q_{2}^{2}} q_{1}\right]\right)\right] \\
& \frac{d \bar{q}_{1}}{d \theta}=\frac{\psi^{\prime \prime}+\frac{\lambda}{1+\lambda} \frac{\nu}{1+\nu} \phi^{\prime \prime}}{D}\left[-q_{1}\left(S^{\prime \prime}+\theta+\lambda\left[\frac{\partial^{2} p_{1}}{\partial q_{1} \partial q_{2}} q_{1}+\frac{\partial p_{1}}{\partial q_{2}}\right]\right)+q_{2}\left(S^{\prime \prime}+\lambda\left[\frac{\partial^{2} p_{1}}{\partial q_{2}^{2}} q_{1}\right]\right)\right] \\
& \frac{d \bar{q}_{2}}{d \theta}=\frac{1}{D}\left[-q_{1}\left[\left(S^{\prime \prime}+\lambda\left[\frac{\partial^{2} p_{1}}{\partial q_{1}^{2}}+2 \frac{\partial p_{1}}{\partial q_{1}}\right]\right)\left(-\psi^{\prime \prime}-\frac{\lambda}{1+\lambda} \frac{\nu}{1+\nu} \phi^{\prime \prime}\right)-(1+\lambda)\right]\right. \\
& \left.+q_{2}\left(S^{\prime \prime}+\theta+\lambda\left[\frac{\partial^{2} p_{1}}{\partial q_{1} \partial q_{2}} q_{1}+\frac{\partial p_{1}}{\partial q_{2}}\right]\right)\left(-\psi^{\prime \prime}-\frac{\lambda}{1+\lambda} \frac{\nu}{1+\nu} \phi^{\prime \prime}\right)\right] \\
& \frac{d \bar{e}}{d \theta}=\frac{1}{D}\left[-q_{1}\left(S^{\prime \prime}+\theta+\lambda\left[\frac{\partial^{2} p_{1}}{\partial q_{1} \partial q_{2}} q_{1}+\frac{\partial p_{1}}{\partial q_{2}}\right]\right)+q_{2}\left(S^{\prime \prime}+\lambda\left[\frac{\partial^{2} p_{1}}{\partial q_{2}^{2}} q_{1}\right]\right)\right]
\end{aligned}
$$

where $S^{\prime \prime}+\lambda\left[\frac{\partial^{2} p_{1}}{\partial q_{2}^{2}} q_{1}\right]<0$ by the second order conditions, leading to:

$$
\operatorname{SIGN}\left(\frac{d q_{1}}{d \theta}\right)=\operatorname{SIGN}\left(\frac{d e}{d \theta}\right)
$$

Therefore,

- if $S^{\prime \prime}+\theta+\lambda\left[\frac{\partial^{2} p_{1}}{\partial q_{1} \partial q_{2}} q_{1}+\frac{\partial p_{1}}{\partial q_{2}}\right]>0$, then

$$
\frac{d q_{2}}{d \theta}>0, \frac{d q_{1}}{d \theta}>0, \frac{d e}{d \theta}>0
$$

- otherwise, if $\left|S^{\prime \prime}+\theta+\lambda\left[\frac{\partial^{2} p_{1}}{\partial q_{1} \partial q_{2}} q_{1}+\frac{\partial p_{1}}{\partial q_{2}}\right]\right|$ is large enough relative to $\left|S^{\prime \prime}+\lambda\left[\frac{\partial^{2} p_{1}}{\partial q_{2}^{2}} q_{1}\right]\right|$, the substitution effect dominates and

$$
\frac{d q_{2}}{d \theta}<0, \frac{d q_{1}}{d \theta}<0, \frac{d e}{d \theta}<0
$$


As for the intensity of incentives $k$, we obtain similar results as in the case of a change in $c$. We have

$$
\frac{d k}{d \theta}=\frac{1}{q_{1}} \psi^{\prime \prime} \frac{d e}{d \theta}+\psi^{\prime}\left(-\frac{1}{q_{1}^{2}}\right) \frac{d q_{1}}{d \theta} .
$$

Since $\frac{d \underline{e}}{d \bar{\theta}} \psi^{\prime \prime}=\frac{d \underline{q}_{1}}{d \theta}$ and $\frac{d \bar{e}}{d \theta}\left[\psi^{\prime \prime}+\frac{\nu}{1-\nu} \frac{\lambda}{1+\lambda} \phi^{\prime \prime}\right]=\frac{d \bar{q}_{1}}{d \theta}$, we obtain

$$
\begin{gathered}
\frac{d \underline{k}}{d \theta}=\frac{1}{\underline{q}_{1}}\left[1-\frac{\psi^{\prime}(\underline{e})}{\underline{q}_{1}}\right] \frac{d \underline{q}_{1}}{d \theta}=0 \\
\frac{d \bar{k}}{d \theta}=\frac{1}{\bar{q}_{1}}\left[\frac{\psi^{\prime \prime}(\bar{e})}{\psi^{\prime \prime}(\bar{e})+\frac{\nu}{1-\nu} \frac{\lambda}{1+\lambda} \phi^{\prime \prime}(\bar{e})}-\frac{\psi^{\prime}(\bar{e})}{\bar{q}_{1}}\right] \frac{d \bar{q}_{1}}{d \theta} .
\end{gathered}
$$

The intensity of incentives for the good type remains constant but, for $\lambda$ sufficiently large and $\phi^{\prime \prime} \neq 0$,

$$
\operatorname{SIGN}\left(\frac{d \bar{k}}{d \theta}\right)=-\operatorname{SIGN}\left(\frac{d \bar{q}_{1}}{d \theta}\right)
$$




\section{References}

[1] Anton, J. and Yao, D. (1989), "Split Awards, Procurement, and Innovation", Rand Journal of Economics 30, 538-552.

[2] Anton, J. and Yao, D. (1992), "Coordination in Split Award Auctions", Quarterly Journal of Economics 107, 681-708.

[3] Auriol, E. and Laffont, J.J. (1992), "Regulation by Duopoly", Journal of Economics and Management Strategy 1, 507-533.

[4] Bliss, C. and Di Tella, R. (1997), "Does Competition Kill Corruption?”, Journal of Political Economy 105, 1001-1023.

[5] Boyer, M. and Laffont, J.J. (1998), "Toward a Political Theory of the Emergence of Environmental Incentive Regulation," Rand Journal of Economics 30, 137-157.

[6] Crémer, J. and McLean, R. (1985), "Optimal Selling Strategies under Uncertainty for a Discriminating Monopolist when Demands are Interdependent," Econometrica 53, 345-361.

[7] Crémer, J. and McLean, R. (1988), "Full Extraction of the Surplus in Bayesian and Dominant Strategy Auctions," Econometrica 56, 1247-1258.

[8] Dana, J. and Speir, K. (1994), "Designing a Private Industry: Government Auctions with Endogenous Market Structure", Journal of Economic Theory 53, 127-147.

[9] Hart, O. (1983), "The Market as an Incentive Mechanism", Bell Journal of Economics 14, 366-382.

[10] Hermalin, B. (1992), "The Effects of Competition on Executive Behavior", Rand Journal of Economics 23, 350-365.

[11] Hermalin, B. (1994), "Heterogeneity in organizational Form: Why Otherwise Identical Firms Choose Different Incentives for their Managers", Rand Journal of Economics 25, 518-537.

[12] Holmström, B. (1982), "Moral Hazard in Teams", Bell Journal of Economics 13, 392-415. 
[13] Jeon, D.S. and Laffont, J.J. (1999), "Efficient Downsizing with Adverse Selection," World Bank Economic Review 13, 67-88.

[14] Laffont, J.J. and N'Guessan, T.T. (1999), "Competition and Corruption in an Agency Model," Journal of Economic Development 60, 271-295.

[15] Laffont, J.J. and Tirole, J. (1987), "Auctioning Incentive Contracts," Journal of Political Economy 95, 921-937.

[16] Laffont, J.J. and Tirole, J. (1993), A Theory of Incentives in Procurement and Regulation, MIT Press, Cambridge.

[17] Leibenstein, H. (1996), "Allocative Efficiency vs. 'X-Efficiency'”, American Economic Review 56, 392-415.

[18] LeGallo, V. (1998), “Compulsory Competitive Tendering: The U.K. Experience," mimeo, CIRANO (Montréal).

[19] Machlup, F (1967), "Theories of the Firm: Marginalist, Behavioral, Managerial”, American Economic Review 57, 1-33.

[20] Mirrlees, J. (1974), "Notes on Welfare Economics, Information, and Uncertainty", in Balch, M., McFadden, D., and S. Wu (eds), Essays in Equilibrium Behavior, Amsterdam, NorthHolland.

[21] Nalebuff, B. and Stiglitz, J. (1983), "Information, Competition, and Markets", American Economic Review, Papers and Proceedings 73, 278-283.

[22] Riordan, M. and Sappington, D. (1988), "Optimal Contracts with Ex Post Information," Journal of Economic Theory 45, 189-199.

[23] Scharfstein, D. (1988), "Product Market Competition and Managerial Slack", Rand Journal of Economics 19, 147-155.

[24] Shleifer, A (1985), "A Theory of Yardstick Competition", Rand Journal of Economics 16, 319-327.

[25] Schmidt, K. (1997), "Managerial Incentives and Product Market Competition", Review of Economic Studies 64, 191-213. 
[26] Tirole, J. (1986), "Hierarchies and Bureaucracies", Journal of Law, Economics and Organization 2, 181-214. 


\section{Liste des publications au CIRANO *}

\section{Cahiers CIRANO / CIRANO Papers (ISSN 1198-8169)}

99c-1 Les Expos, l'OSM, les universités, les hôpitaux : Le coût d'un déficit de 400000 emplois au Québec — Expos, Montréal Symphony Orchestra, Universities, Hospitals: The Cost of a 400,000-Job Shortfall in Québec / Marcel Boyer

96c-1 Peut-on créer des emplois en réglementant le temps de travail? / Robert Lacroix

95c-2 Anomalies de marché et sélection des titres au Canada / Richard Guay, Jean-François L'Her et Jean-Marc Suret

95c-1 La réglementation incitative / Marcel Boyer

94c-3 L'importance relative des gouvernements: causes, conséquences et organisations alternative / Claude Montmarquette

94c-2 Commercial Bankruptcy and Financial Reorganization in Canada / Jocelyn Martel

94c-1 Faire ou faire faire : La perspective de l'économie des organisations / Michel Patry

\section{Série Scientifique / Scientific Series (ISSN 1198-8177)}

2000s-57 Law versus Regulation: A Political Economy Model of Instrument Choice in Environmental Policy / Marcel Boyer et Donatella Porrini

2000s-56 Le retour à l'école / Marcel Dagenais, Claude Montmarquette, Nathalie Viennot-Briot et Muriel Meunier

2000s-55 Le décrochage scolaire, la performance scolaire et le travail pendant les études : un modèle avec groupe hétérogène / Marcel Dagenais, Claude Montmarquette, Nathalie Viennot-Briot et Muriel Meunier

2000s-54 Vertical R\&D Spillovers, Cooperation, Market Structure, and Innovation / Gamal Atallah

2000s-53 Information Sharing and the Stability of Cooperation in Research Joint Ventures / Gamal Atallah

2000s-52 A Theory of Routines as Mindsavers / Bernard Sinclair-Desgagné et Antoine Soubeyran

2000s-51 Can Financial Intermediation Induce Economic Fluctuations? / Sanjay Banerji et Ngo Van Long

2000s-50 Information Technology Sophistication in Hospitals: A Field Study in Quebec / Guy Paré et Claude Sicotte

2000s-49 Does Comparable Worth Work in a Decentralized Labor Market? / Michael Baker et Nicole M. Fortin

2000s-48 Occupational Gender Composition and Wages in Canada: 1987-1988 / Michael Baker et Nicole M. Fortin

\footnotetext{
* Vous pouvez consulter la liste complète des publications du CIRANO et les publications elles-mêmes sur notre site Internet à l'adresse suivante :
}

http://www.cirano.umontreal.ca/publication/documents.html 